\title{
Pathogenesis of Congenital Alkalosis with Diarrhea
}

\author{
IMPLICATIONS FOR THE PHYSIOLOGY OF NORMAL \\ ILEAL ELECTROLYTE ABSORPTION AND SECRETION
}

\author{
Frederick A. Bieberdorf, Phillip Gorden, and John S. Fordtran \\ From the Department of Internal Medicine, The University of Texas South- \\ western Medical School at Dallas, Dallas, Texas 75235, and the National \\ Institute of Arthritis and Metabolic Diseases, National Institutes of Health, \\ Bethesda, Maryland 20014
}

\begin{abstract}
A в S T R A C T Using a triple-lumen constant perfusion system, we have studied ileal electrolyte transport in a patient with congenital alkalosis with diarrhea and made the following observations. First, chloride cannot be transported against electrochemical gradients, but can be readily absorbed or secreted down electrochemical gradients. Second, chloride secretion down an electrochemical gradient can be increased by raising lumen bicarbonate concentration. Third, sodium absorption does occur against electrochemical gradients and is associated with hydrogen ion secretion. Fourth, electrical potential difference (PD) between lumen and blood is near zero when lumen sodium concentration is 140 $\mathrm{mEq} /$ liter. Fifth, a normal sodium diffusion potential is present. Sixth, potassium is transported passively in response to electrochemical gradients.

The ileal electrolyte transport disorder of congenital alkalosis with diarrhea can be simulated exactly in normal subjects perfused with a solution in which chloride is replaced with poorly absorbable sulfate and phosphate.

These results can be explained by postulating a single defect in the double ion exchange model (sodium-hydrogen, chloride-bicarbonate) previously proposed for normal ileal transport: i.e., normal sodium-hydrogen exchange, but a chloride-bicarbonate exchange that is incapable of transporting chloride against an electrochemical gradient, yet continues to transport anions passively. In contrast, the results appear incompatible with the concept of ileal electrogenic sodium transport.
\end{abstract}

Received for publication 29 November 1971 and in revised form 23 February 1972.

\section{INTRODUCTION}

In 1945, Darrow and Gamble separately described two infants with metabolic alkalosis and diarrhea from birth $(1,2)$. They demonstrated hypochloremia, a high stool chloride concentration, and an absence of chloride in the urine. They termed this syndrome congenital alkalosis with diarrhea. Subsequently, four additional cases have been reported (3-6), sometimes under the name of congenital chloridorrhea. In contrast to all other diarrheal states the stool chloride concentration is consistently greater than the sum of the sodium and potassium concentrations.

The pathogenesis of this disorder is not entirely clear. The cation gap in fecal water and the systemic alkalosis suggest the possibility of acid secretion into the gut lumen. One early suggestion was secretion of hydrochloric acid by aberrant gastric mucosa; however, a careful autopsy of Gamble's patient failed to reveal evidence of gastric mucosal remnants anywhere in the small or large intestine (2). Evanson and Stanbury's extensive balance studies on their patient suggested that chloride absorption was defective, and that chloride ingested orally or secreted into the gut acted as an osmotic cathartic, and thus produced diarrhea. They attributed the alkalosis to potassium and chloride deficiencies incurred by fecal losses of these ions. The low bicarbonate concentration in stool suggested to these workers a defect in the intestinal exchange mechanism which absorbs chloride and secretes bicarbonate (6). Turnberg recently studied Evanson and Stanbury's patient using an intestinal perfusion technique and noted chloride secretion against a concentration gradient in the ileum (7). 
From the standpoint of normal human physiology and for a better understanding of the pathogenesis of diarrhea, congenital alkalosis with diarrhea is a disorder of special interest and importance. If the disease were due to abnormal secretion, study of this disease might add greatly to our knowledge of human intestinal secretion, previously studied only in sprue $(8,9)$, cholera (10), and acute undifferentiated diarrhea (11). On the other hand, if the disease were caused by a congenital deletion of a normal absorptive mechanism, study of the disorder would almost certainly enhance our knowledge of normal absorptive processes.

The present report describes ileal perfusion studies on an adult with congenital alkalosis with diarrhea. $\mathrm{He}$ is R. A., the patient Darrow originally described in 1945 (1). He is now $29 \mathrm{yr}$ old and has had lifelong metabolic alkalosis and diarrhea (1-3 liters/day) with stools containing chloride in excess of sodium and potassium. ${ }^{1}$

Our experiments have revealed two striking abnormalities in R. A.: first, his ileal mucosa is not capable of active chloride absorption; second, when perfused with an electrolyte solution similar to normal intestinal contents, his ileum acidifies rather than alkalinizes this solution. These abnormalities help explain the pathogenesis of congenital alkalosis with diarrhea and also have relevance to normal mechanisms of electrolyte transport.

\section{METHODS}

The experiments on R. A. were conducted in April 1970, July 1970, and February 1971. 15 1-hr perfusion studies were performed on this patient. The control subjects were normal volunteer men and women, aged $21-40 \mathrm{yr}$. The triple-lumen perfusion technique was used as described before in detail (12). The infusion tip was $10 \mathrm{~cm}$ above the proximal aspiration site, and the distance between proximal and distal aspiration sites was $30 \mathrm{~cm}$. The nonabsorbable marker was polyethylene glycol (PEG), ${ }^{2} 5 \mathrm{~g} /$ liter. Studies on $\mathrm{R}$. A. were done with the infusion tip $180-200 \mathrm{~cm}$ from the teeth. Studies in normal subjects were done with the infusion tip 190-230 $\mathrm{cm}$ from the teeth. The perfusion rate was $10 \mathrm{ml} / \mathrm{min}$. All solutions (except where noted) were bubbled with $7 \% \mathrm{CO}_{2}$ for 30 min before and during each study period. All perfusion solutions were isotonic to plasma. Sodium concentrations were $140 \mathrm{mEq} /$ liter except where noted. Sulfate and mannitol were present in some solutions to achieve ionic balance and isotonicity. A balanced electrolyte solution, simulating the electrolyte composition of normal plasma, was used in several experiments.

Electrolyte concentrations were measured by standard meihods, and PEG by the method of Hyden (13). Total $\mathrm{CO}_{2}$ was measured using a Natelson microgasometer (Model 600, Scientific Industries, Inc., Springfield, Mass.). $\mathrm{pH}$

\footnotetext{
${ }^{1}$ Gorden, P., and H. Levitin. Clinical course, systemic acid-base and balance studies will be described in a manuscript currently in preparation.

${ }^{2}$ Abbreviations used in this paper: EC, electrochemical; $\mathrm{PD}$, potential difference; PEG, polyethylene glycol.
}

and $\mathrm{P}_{\mathrm{CO}_{2}}$ were measured on a Duo-matic $\mathrm{pH} / \mathrm{P}_{\mathrm{Co}_{2}}$ analyzer (Instrumentation Laboratory, Inc., Watertown, Mass.). Electrolyte absorption and secretion rates were calculated from the perfusion rate, the change in PEG concentration, and the change in concentration of the electrolyte. Results are expressed as mean values \pm 1 sEM. The mean concentration of solute in the test segment was calculated by averaging the concentration in fluid samples from the proximal and distal sites.

Unidirectional chloride flux rates were determined by including $0.5 \mu \mathrm{Ci} /$ liter ${ }^{36} \mathrm{C} 1$ in some solutions. Calculations were done by the method of Berger and Steele (14).

Electrical potential difference (PD) between lumen and blood was determined in $R$. A. during six perfusion experiments (three experiments on two separate occasions). Measurements were made for $1 \mathrm{hr}$ during each perfusion study at $1 \mathrm{~min}$ intervals between a luminal electrode in the middle of the test segment and abraded skin. The preparation of this electrode was described in an earlier publication (12). It was shown previously that the PD between abraded skin and peritoneum is less than $5 \mathrm{mv}$, so the lumen to skin PD should be nearly equal to the lumen to peritoneum PD (15). Because of the critical importance of the absolute level of $P D$ in $R$. A., we also measured the PD between abraded skin and blood during each study, using a 13-gauge Teflon catheter containing blood as a salt bridge between a large vein and a calomel electrode. This PD (2-5 mv) was used to convert lumen-skin PD to lumenblood PD.

The ionic makeup of jejunal contents on $R$. A. after a standard meal was measured by a previously described method (16). Basal gastric acid secretion and peak response to histamine were measured using a Sargent $\mathrm{pH}$ meter, hydrogen ion concentration measured by method of Moore and Scarlata (17).

\section{RESULTS}

\section{Ileal chloride transport in R. A.}

Chloride transport at varying electrochemical gradients. The ability of R. A.'s ileum to absorb or secrete chloride was assessed by varying lumen to blood electrochemical (EC) gradients. EC gradients were varied by altering sodium and chloride concentrations in perfused solutions. All solutions contained $35-40 \mathrm{mEq} /$ liter bicarbonate and 3-5 mEq/liter potassium and were made isotonic with mannitol. As shown in Fig. 1, chloride absorption occurred at lumen concentrations of 116,120 , and $121 \mathrm{mEq} /$ liter chloride, while secretion occurred at concentrations of $73 \mathrm{mEq} /$ liter and below. The regression line crosses zero movement at a lumen chloride concentration of $77 \mathrm{mEq} /$ liter. The value is close to his average serum chloride concentration of $84 \mathrm{mEq} /$ liter, suggesting that there is little, if any, net movement of chloride against a concentration gradient. In contrast, normal subjects are able to absorb chloride from test solutions containing as little as $20 \mathrm{mEq} /$ liter chloride (15).

The ileal mucosa to blood electrical PD is discussed in a subsequent section, but for present purposes, it should be noted that PD was measured simultaneously 


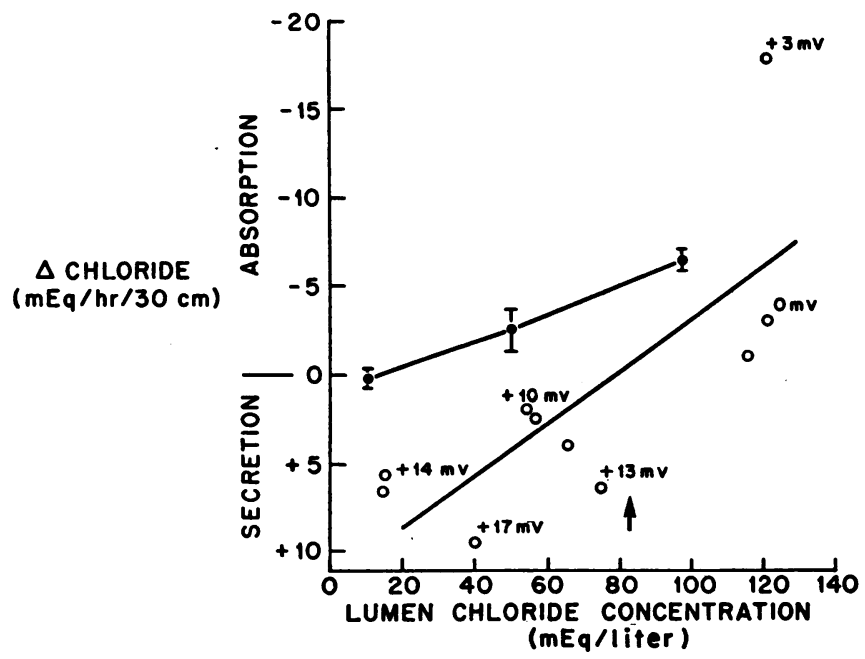

FIgURE 1 Effect of lumen chloride concentration on net chloride movement in $R$. A. and normal subjects. Sodium concentration was approximately $30 \mathrm{mEq} /$ liter higher than chloride concentration. Data obtained in R. A. are shown as individual points. The regression line was drawn by method of least squares $(r=0.73)$. Electrical potential difference $(P D)$ between ileal lumen and blood is shown for six points in $R$. A. The positive sign preceding $P D$ values indicates lumen is positive compared to blood. The vertical arrow represents R. A.'s average serum chloride concentration during the studies. Data obtained in nine normal subjects are shown as mean values \pm 1 SEM for comparison.

in 6 of the 10 studies shown in Fig. 1 and when EC concentration gradients were related by the Nernst equation, there was no evidence for net chloride transport against an electrochemical gradient. Thus, active chloride transport was not observed in R. A.'s ileum. However, it is clear that passive chloride absorption and secretion do occur in this patient.

Unidirectional chloride fuxes. Unidirectional chloride fluxes using ${ }^{\star} \mathrm{C} 1$ in the perfusate were measured

TABLE I

Unidirectional Chloride Fluxes in R. A. and Four Normal Subjects during Perfusion of Balanced Electrolyte Solution

\begin{tabular}{|c|c|c|c|c|}
\hline & \multirow[b]{2}{*}{$\begin{array}{c}\text { Lumen } \\
{[\mathrm{Cl}]}\end{array}$} & \multirow[b]{2}{*}{ Net $\Delta \mathrm{Cl}$} & \multicolumn{2}{|c|}{ Unidirectional flux } \\
\hline & & & $\begin{array}{l}\text { Lumen } \\
\text { to blood }\end{array}$ & $\begin{array}{l}\text { Blood } \\
\text { to lumen }\end{array}$ \\
\hline & $m E q / l i t e r$ & $m E q / h r / 30 \mathrm{~cm}$ & & \\
\hline R. A. & 121 & -3.1 & 11.5 & 8.4 \\
\hline \multicolumn{5}{|c|}{ Normal subjects } \\
\hline J. M. & 110 & -12.2 & 19.2 & 7.0 \\
\hline J. T. & 115 & -1.8 & 13.3 & 11.5 \\
\hline D. C. & 108 & -6.8 & 13.3 & 6.5 \\
\hline G. W. & 113 & -11.5 & 20.2 & 8.7 \\
\hline
\end{tabular}

A negative sign denotes absorption. during perfusion of the balanced electrolyte solution in R. A. and in four normal subjects and the results are shown in Table I. In the normal subjects the lumen to blood chloride flux varied between 13.3 and 20.2. In R. A., this flux was 11.5 , which is close to the lower values found in normal subjects. The blood to lumen chloride flux in R. A. was within the range found in normal subjects. These results suggest that ileal mucosal permeability to chloride is not markedly reduced in R. A.

Effect of bicarbonate concentration on chloride transport. In normal subjects the rate of ileal chloride transport is affected by lumen bicarbonate concentration (15). In order to see if bicarbonate affected chloride transport in $R$. A., lumen bicarbonate concentration was varied while lumen chloride concentration was maintained at $50-55 \mathrm{mEq} /$ liter. When lumen bicarbonate concentration was changed from 30 to $81 \mathrm{mEq} /$ liter, bicarbonate absorption increased from 3.2 to 5.5 $\mathrm{mEq} / \mathrm{hr}$ per $30 \mathrm{~cm}$, and chloride secretion increased from 1.8 to $3.8 \mathrm{mEq} / \mathrm{hr}$ per $30 \mathrm{~cm}$. Thus, increasing bicarbonate concentration, and thereby its absorption, appeared to stimulate chloride secretion. These results are qualitatively similar to data previously reported in normal subjects (15), and suggest reciprocal bicarbon- 
TABLE II

Ileal Ion Movement and $p H$ during Perfusion of Balanced Electrolyte Solution

\begin{tabular}{|c|c|c|c|c|c|c|c|c|c|c|c|c|}
\hline & \multirow[b]{2}{*}{$\Delta \mathrm{H}_{2} \mathrm{O}$} & \multirow[b]{2}{*}[\mathrm{Na}]{} & \multirow[b]{2}{*}{$\Delta \mathrm{Na}$} & \multirow[b]{2}{*}[\mathrm{K}]{} & \multirow[b]{2}{*}{$\Delta \mathrm{K}$} & \multirow[b]{2}{*}[\mathrm{Cl}]{} & \multirow[b]{2}{*}{$\Delta \mathrm{Cl}$} & \multirow[b]{2}{*}[\mathrm{HCO}_{3}]{} & \multirow[b]{2}{*}{$\triangle \mathrm{HCO}_{3}$} & \multicolumn{3}{|c|}{$\mathrm{pH}$} \\
\hline & & & & & & & & & & Inf & Prox & Dist \\
\hline \multicolumn{13}{|l|}{ R. A. } \\
\hline a & -55 & 130 & -7.1 & 4.1 & -0.6 & 116 & -1.2 & 15 & -5.5 & 7.50 & 7.05 & 6.98 \\
\hline b & -70 & 147 & -9.8 & 3.0 & -0.1 & 121 & -3.1 & 23 & -6.2 & 7.45 & 7.20 & 7.00 \\
\hline c & -212 & 139 & -29.0 & 3.6 & -0.7 & 119 & -18.2 & 20 & -10.9 & - & 7.32 & 6.83 \\
\hline \multicolumn{13}{|c|}{ Normal subjects } \\
\hline$n=6$ & -25 & 141 & -3.5 & 5.3 & 0.0 & 99 & -4.1 & 34 & +0.6 & 7.38 & 7.39 & 7.47 \\
\hline & \pm 10 & \pm 1 & \pm 1.5 & \pm 0.1 & \pm 0.1 & \pm 2 & \pm 1.3 & \pm 3 & \pm 0.3 & \pm 0.02 & \pm 0.02 & \pm 0.04 \\
\hline
\end{tabular}

Units are milliequivalents per liter for concentration and milliequivalents per hour per $30 \mathrm{~cm}$ for absorption or secretion rate. A negative sign denotes absorption, a positive sign secretion. Concentrations are mean concentrations in test segment.

ate and chloride movement, as by an anion exchange process.

\section{Ileal sodium transport in R. A.}

Sodium transport at varying sodium concentrations. Ileal sodium transport was measured during perfusion of the test solutions used to assess chloride transport. In these studies sodium was absorbed until lumen sodium concentration was as low as $62 \mathrm{mEq} / \mathrm{liter}, 78$ $\mathrm{mEq} /$ liter below his plasma sodium concentration. However, as sodium concentration was lowered, sodium absorption was favored by a lumen positive electrical $P D$. By the Nernst equation, electrical PD would have to be at least $23 \mathrm{mv}$ to account for passive sodium absorption down to a lumen sodium concentration of $62 \mathrm{mEq} /$ liter. Measured electrical PD values did not exceed $17 \mathrm{mv}$ in any of these studies, even at much lower lumen sodium concentrations, indicating that in R. A. ileal sodium absorption does occur against electrochemical gradients. When lumen sodium was less than $62 \mathrm{mEq} /$ liter, sodium was secreted. In normal subjects sodium absorption occurs down to lumen concentration of $27 \mathrm{mEq} /$ liter (15).

Sodium absorption from balanced electrolyte solution. Sodium absorption was measured in R. A.'s ileum on three occasions during perfusion of a balanced electrolyte solution, simulating the electrolyte composition of normal plasma. These studies are contrasted to similar studies in normal subjects in Table II. In all three instances he absorbed more sodium than did the normal subjects. This sodium absorption occurred in the presence of a normal lumen to blood electrical PD (described in a subsequent section). Thus, the ability of R. A.'s ileum to absorb sodium from a balanced electrolyte solution is not impaired, and, in fact, is greater than that of any normal subjects we have studied.

Effect of bicarbonate on sodium absorption. In the studies of sodium absorption described in Table II, R. A. absorbed large amounts of bicarbonate along with sodium, whereas the normal subjects absorbed sodium chloride and secreted a small amount of bicarbonate. In order to see if sodium absorption and bicarbonate absorption in $\mathrm{R}$. A. could be dissociated (that is, occur independently), sodium absorption from a bicarbonate-containing and a bicarbonate-free solution was measured and is shown in Table III. Both solutions had similar sodium and chloride concentrations. One solution contained bicarbonate, the other contained sulfate instead of bicarbonate. Both solutions were isotonic to plasma. As shown in Table III, omission of bicarbonate completely inhibited sodium absorption. Thus, ileal sodium absorption in R. A. requires the presence of bicarbonate in the lumen. In contrast, omission of bicarbonate does not reduce sodium absorption in normal subjects (12).

\section{Bicarbonate absorption in R. A.}

Absorption of bicarbonate from the balanced electrolyte solution in R. A. might occur by either of two mechanisms. First, bicarbonate ion might be absorbed per se, or, second, hydrogen ion might be secreted and react with bicarbonate in the lumen to form carbonic acid. Either process would cause apparent bicarbonate absorption and acidification of ileal contents. However, hydrogen secretion would elevate lumen $\mathrm{P}_{\mathrm{co}}$ above a basal level, while bicarbonate absorption would cause a fall in $\mathrm{P}_{\mathrm{co}_{2}}$ (18). The presence of a nonbicarbonate

TABLE III

Ion Movement in the Presence and Absence of Bicarbonate in $R$. A.

\begin{tabular}{lcccccc}
\hline & {$[\mathrm{Na}]$} & $\Delta \mathrm{Na}$ & {$[\mathrm{Cl}]$} & $\Delta \mathrm{Cl}$ & {$\left[\mathrm{HCO}_{3}\right]$} & $\Delta \mathrm{HCO}_{3}$ \\
\hline HCO & & & & \\
HContaining solution & 139 & -29.0 & 119 & -18.2 & 20.2 & -10.9 \\
& 139 & +3.1 & 109 & +2.5 & 3.3 & +0.8
\end{tabular}

Units are millequivalents per liter for concentration and milliequivalents per hour per $30 \mathrm{~cm}$ for absorption or secretion rate. A negative sign denotes absorption, a positive sign secretion.

* $\mathrm{HCO}_{2}$ replaced by $\mathrm{SO}_{4}$ and mannitol. 
TABLE IV

Ileal $p H$ and $\mathrm{PCO}_{2}$ in Presence and Absence of Bicarbonate in $\mathrm{R}$. A.

\begin{tabular}{|c|c|c|c|c|c|c|c|c|c|}
\hline & \multicolumn{2}{|c|}{$\left[\mathrm{HCO}_{3}\right]$} & \multirow[b]{2}{*}{$\triangle \mathrm{HCO}_{3}$} & \multicolumn{3}{|c|}{$\mathrm{pH}$} & \multicolumn{3}{|c|}{$\mathrm{Pco}_{2}$} \\
\hline & Proximal & Distal & & Infusion & Proximal & Distal & Infusion & Proximal & Distal \\
\hline & \multicolumn{2}{|c|}{$m E q /$ liter } & $m E q / h r / 30 \mathrm{~cm}$ & & & & & $m m \mathrm{Hg}$ & \\
\hline \multicolumn{10}{|c|}{$\mathrm{HCO}_{3}$-containing solutions } \\
\hline $\mathbf{a}$ & 30.5 & 20.4 & -5.9 & 7.52 & 7.24 & 7.09 & 55 & 77 & 75 \\
\hline b & 28.0 & 18.3 & -6.2 & 7.45 & 7.20 & 7.00 & 62 & 73 & 73 \\
\hline c & 33.8 & 24.2 & -5.0 & 7.59 & 7.34 & 7.14 & 62 & 78 & 76 \\
\hline d & - & 12.3 & - & 7.44 & - & 6.70 & 64 & - & 74 \\
\hline e & 28.9 & 11.5 & -10.9 & 一 & 7.32 & 6.83 & - & 58 & 72 \\
\hline f & 23.9 & 9.1 & -8.8 & - & 7.21 & 6.73 & 一 & 62 & 68 \\
\hline $\mathrm{g}$ & 26.1 & 17.3 & -5.3 & - & 7.32 & 7.05 & - & 62 & 71 \\
\hline \multicolumn{10}{|c|}{$\mathrm{HCO}_{3}$-free solutions } \\
\hline h & 4.9 & 4.1 & -0.4 & 6.85 & 6.32 & 6.12 & 62 & 61 & 62 \\
\hline $\mathrm{i}$ & 2.3 & 3.1 & +0.5 & 4.85 & 5.87 & 6.08 & 60 & 60 & 64 \\
\hline $\mathrm{j}$ & 2.7 & 3.8 & +0.8 & 4.80 & 6.07 & 6.08 & 56 & 60 & 64 \\
\hline
\end{tabular}

Test solutions for studies $d$ and $h$ contained $15 \mathrm{~mm} \mathrm{PO}$ as a buffer, while $a, b, c, e, f$, and g contained only $\mathrm{Na}, \mathrm{K}, \mathrm{Cl}$, and $\mathrm{HCO}_{3}$. Test solutions for studies $\mathrm{h}-\mathrm{j}$ were similar to those for a-g except that $\mathrm{HCO}_{3}$ was replaced by $\mathrm{SO}_{4}$. Test solutions for a-d and $\mathrm{h}-\mathrm{j}$ were gassed with $7 \% \mathrm{CO}_{2}$ before infusion, while solutions for $e, f$, and $g$ were equilibrated with room air.

buffer such as phosphate theoretically should amplify the effect of hydrogen ion secretion on lumen $\mathrm{Pco}_{2}$ (18).

Changes in bicarbonate concentration, $\mathrm{pH}$ and $\mathrm{Pco}_{2}$ of bicarbonate-containing solutions from which bicarbonate was absorbed were measured and compared with changes in $\mathrm{pH}$ and $\mathrm{Pco}_{2}$ of control bicarbonate-free test solutions. The results are shown in Table IV. Seven solutions contained bicarbonate. As bicarbonate was absorbed, $\mathrm{pH}$ fell and $\mathrm{Pco}_{2}$ rose to $68-76 \mathrm{~mm} \mathrm{Hg}$. Three solutions contained no bicarbonate. The $\mathrm{pH}$ of these solutions approached 6.1, while $\mathrm{Pco}_{2}$ remained below $65 \mathrm{~mm} \mathrm{Hg}$. Thus, the lumen $\mathrm{Pco}_{2}$ becomes elevated when bicarbonate is present in the ileum. No effect of including phosphate buffer in the perfusate (solutions $\mathrm{d}$ and $\mathrm{h}$ ) was apparent. Some bicarbonate-containing solutions ( $e, f$, and $g$ ) were not equilibrated with $\mathrm{CO}_{2}$ before infusion. These studies demonstrate a rise in $\mathrm{PCO}_{2}$ between proximal and distal sites, i.e., in the test segment where bicarbonate absorption was measured.

TABLE V

$P D$ at Different Lumen Ion Concentrations in $R$. A.

\begin{tabular}{lrrrr}
\hline \multicolumn{1}{c}{ Test solution } & {$[\mathrm{Na}]$} & {$[\mathrm{Cl}]$} & {$[\mathrm{HCO}]$} & PD \\
\hline Balanced electrolyte & 139 & 119 & 20 & 0 \\
$\mathrm{NaCl}$ partially replaced by mannitol & 79 & 56 & 25 & +10 \\
$\mathrm{NaCl}$ completely replaced by mannitol & 36 & 16 & 20 & +14 \\
$\mathrm{Na} \mathrm{SO}_{4}$ & 137 & 16 & 2 & 0 \\
\hline
\end{tabular}

Ion concentrations are milliequivalents per liter. PD is expressed in millivolts, lumen polarity.
Therefore, the elevated $\mathrm{Pco}_{2}$ cannot be explained by mixture above the test segment of infused bicarbonate and acid lumen contents from higher in the small intestine. These results indicate the bicarbonate absorption seen in R. A. is associated with an elevation of lumen $\mathrm{PCO}_{2}$ and this observation suggests that bicarbonate absorption is mediated by hydrogen ion secretion and not by actual bicarbonate ion absorption.

Ileal hydrogen secretion might occur by at least two mechanisms. First, secretion of hydrogen against a concentration gradient might be passive, down an electrical gradient generated by active electrogenic sodium absorption. Alternately, hydrogen secretion might be against an electrochemical gradient, perhaps via a nonelectrogenic sodium-hydrogen exchange. In order to determine if this hydrogen ion secretion was in response to an electrical gradient, lumen to blood electrical PD was determined during perfusion of the balanced electrolyte solution (Table II, studies $b$ and $c$ ). During study c, $\mathrm{pH}$ fell from 7.32 at the proximal collecting site down to 6.83 at the distal collecting site. Corresponding bicarbonate concentrations were 28.5 and $11.5 \mathrm{mEq} /$ liter, respectively. Blood bicarbonate concentration was $39 \mathrm{mEq} /$ liter during the study. Thus, the ileum was able to cause lumen bicarbonate concentration to fall to a value less than one-third the plasma bicarbonate concentration. Generation of such a bicarbonate concentration gradient by hydrogen ion movement down an electrical gradient would require a lumen to blood $\mathrm{PD}$ of at least $34 \mathrm{mv}$, lumen negative. 
The observed lumen to blood PD during this study was $3 \mathrm{mv}$, lumen positive. Generation of the bicarbonate gradient observed in study $b$ by an electrical gradient would require a $\mathrm{PD}$ of at least $21 \mathrm{mv}$, while measured PD was zero. Thus, the hydrogen secretion which generated the observed bicarbonate gradient cannot represent passive hydrogen movement down an electrical gradient and must be mediated by an active process.

\section{PD at different lumen ion concentrations in R. A.}

As shown in Table $\mathrm{V}$, when a balanced electrolyte solution was perfused, the PD was zero. As lumen sodium and chloride concentrations were lowered, the PD became progressively lumen positive. In addition, when chloride and bicarbonate were completely replaced with sulfate but lumen sodium concentration was maintained at blood level, the $\mathrm{PD}$ was again zero. These results are similar to those results obtained in this laboratory on normal subjects (15). An increasing lumen positive $\mathrm{PD}$ as lumen sodium and chloride concentrations are lowered has been interpreted as a sodium diffusion potential, dependent on differential passive permeability to sodium and chloride (15). These observations, which are similar to those in normal subjects, suggest that the normal differential permeability to anions and cations is intact in R. A.

\section{Potassium movement in R. A.}

Potassium movement was evaluated in all 15 1-hr perfusion periods. Serum potassium concentrations were $3.8,2.7$, and $3.1 \mathrm{mEq} /$ liter on the three occasions R. A. was studied. Potassium concentrations of the perfusion solutions were $4.9,2.5$, and $3.5 \mathrm{mEq} /$ liter on the respective occasions. Mean lumen potassium concentration and potassium movement during the three perfusions of the balanced electrolyte solution is shown in Table II. In these studies, while lumen potassium concentration was approximately equal to serum concentration, no potassium secretion was observed during high rates of sodium absorption. Thus, these studies provide no evidence for the presence of a sodiumpotassium exchange.

Potassium in the ileum of normal subjects is believed to be transported passively $(19,20)$. If this is the case in R. A., potassium movement in our studies might vary according to the rate of water absorption or secretion and the electrochemical gradients for potassium across the mucosa.

No correlation between potassium movement and water movement was found during the perfusion of the balanced electrolyte solutions or during all the other perfusion studies. Thus, if potassium movement is affected by water absorption or secretion (solvent drag
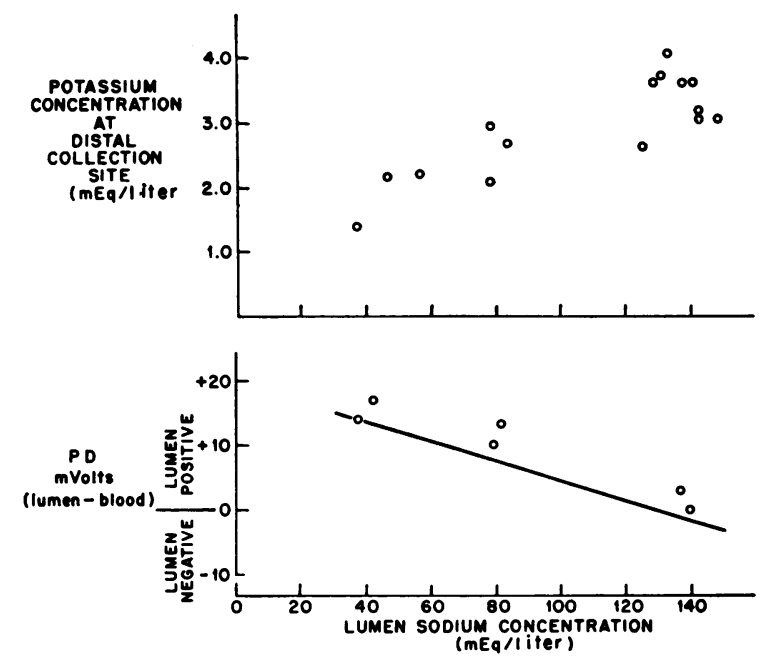

FIGURE 2 Effect of lumen sodium concentration on potassium concentration at the distal collection site and PD calculated from lumen to blood potassium gradients at the distal site. Distal potassium concentrations for all 15 perfusion studies are shown individually. PD necessary to achieve these distal potassium concentrations if distribution of potassium is entirely due to electrochemical gradients is shown in the lower panel as a regression line drawn by method of least squares $(r=0.80)$. PD values measured using an intraluminal electrode are shown for comparison in the lower panel.

effect), this effect is masked by other variables in the studies.

If electrochemical gradients play an important role in the distribution of potassium across the mucosa, potassium concentration at the distal collection site would depend in part on the electrical PD across the mucosa. As shown above, ileal PD can be varied in R. A. by varying lumen sodium concentration. Fig. 2 relates potassium concentration at the distal site to lumen sodium concentration in the 15 studies. As shown in the figure, at the lower lumen sodium concentrations, the distal potassium concentration was decreased. This relationship is not explicable on the basis of the potassium concentration of the perfusion solutions since each perfusion potassium concentration is equally represented at high and low sodium concentrations.

The electrical PD necessary to achieve the unequal distribution of potassium between lumen and blood in R. A. was estimated by the Nernst equation and is shown in Fig. 2 as a line, along with $\mathrm{PD}$ measurements obtained with our electrode. Estimated PD at a sodium concentration of $140 \mathrm{mEq} /$ liter is $1 \mathrm{mv}$, lumen negative, while measured $P D$ was $0 \mathrm{mv}$ and $3 \mathrm{mv}$, lumen positive. At a sodium concentration of $80 \mathrm{mEq}$ / liter corresponding values are $8 \mathrm{mv}$, lumen positive, vs. $10 \mathrm{mv}$ and $13 \mathrm{mv}$, lumen positive. At a sodium concentration of $40 \mathrm{mEq} /$ liter, estimated $\mathrm{PD}$ is $14 \mathrm{mv}$, lumen 
TABLE VI

Effect of Bicarbonate on Ion Movement, $\mathrm{pH}$, and $\mathrm{PCO}_{2}$ during Perfusion of Chloride-Free Test Solutfons in Normal Subjects

\begin{tabular}{|c|c|c|c|c|c|c|c|c|c|c|c|c|c|c|}
\hline \multirow[b]{2}{*}{$\Delta \mathrm{H}_{2} \mathrm{O}$} & \multirow[b]{2}{*}[\mathrm{Na}]{} & \multirow[b]{2}{*}{$\Delta \mathrm{Na}$} & \multirow[b]{2}{*}[\mathrm{K}]{} & \multirow[b]{2}{*}{$\Delta \mathbf{K}$} & \multirow[b]{2}{*}[\mathrm{Cl}]{} & \multirow[b]{2}{*}{$\Delta \mathrm{Cl}$} & \multirow[b]{2}{*}[\mathrm{HCO}_{2}]{} & \multirow[b]{2}{*}{$\triangle \mathrm{HCO}_{3}$} & \multicolumn{3}{|c|}{$\mathrm{pH}$} & \multicolumn{3}{|c|}{$\mathrm{PcO}_{2}$} \\
\hline & & & & & & & & & Inf & Prox & Dist & Inf & Prox & Dist \\
\hline \multicolumn{15}{|c|}{$\mathrm{HCO}_{3}$-containing, $\mathrm{n}=10$} \\
\hline-33 & 141 & -3.7 & 5.0 & -0.1 & 15.4 & -0.6 & 21.1 & -2.3 & 7.38 & 7.18 & 7.07 & 46.1 & 59.7 & 62.1 \\
\hline \pm 7 & \pm 0.3 & \pm 1.0 & \pm 0.1 & \pm 0.1 & \pm 2.3 & \pm 0.5 & \pm 1.1 & \pm 0.5 & \pm 0.01 & \pm 0.09 & \pm 0.05 & \pm 0.7 & \pm 1.6 & \pm 1.3 \\
\hline \multicolumn{15}{|l|}{$\mathrm{HCO}_{3}$-free, $\mathrm{n}=10$} \\
\hline-24 & 141 & -2.9 & 5.0 & 0.0 & 7.4 & -0.8 & 6.5 & -0.1 & 6.72 & 6.60 & 6.50 & 45.1 & 50.9 & 55.4 \\
\hline \pm 9 & \pm 0.4 & \pm 1.3 & \pm 0.1 & \pm 0.1 & \pm 1.7 & \pm 0.9 & \pm 0.4 & \pm 0.2 & \pm 0.01 & \pm 0.04 & \pm 0.06 & \pm 1.4 & \pm 1.0 & \pm 0.9 \\
\hline
\end{tabular}

Units are milliequivalents per liter for concentration and milliters or milliequivalents per hour per $30 \mathrm{~cm}$ for absorption or secretion rate. A negative sign denotes absorption, a positive sign secretion.

positive, while measured values are $14 \mathrm{mv}$ and $17 \mathrm{mv}$, lumen positive.

Thus, in R. A., as in normal subjects, potassium appears to be transported passively, in response to electrochemical gradients. Estimates of PD from lumen to blood potassium gradients utilizing the Nernst equation agree within $5 \mathrm{mv}$ of values obtained utilizing an intraluminal electrode.

Gastric acid studies in R. A.

Gastric acid secretory studies revealed a basal acid secretory rate of $0.01 \mathrm{mEq} / \mathrm{hr}$ and a peak output of $26.5 \mathrm{mEq} / \mathrm{hr}$. These results are well within the normal range of our laboratory. Thus, R. A. has no defect in gastric hydrochloric acid production.

\section{Jejunal contents after a standard meal in R. A.}

A standard steak meal with $10 \mathrm{~g}$ PEG was given to R. A. Subsequently, distal jejunal contents $(150 \mathrm{~cm}$ from the teeth) were aspirated. Peak PEG, sodium, potassium, and chloride concentrations were $4600 \mathrm{mg} /$ $100 \mathrm{ml}, 137 \mathrm{mEq} /$ liter, $3.9 \mathrm{mEq} /$ liter, and $115 \mathrm{mEq} /$ liter, respectively. All these values are well within the range of values found in normal subjects at that level of small intestine (16). This suggests a normal jejunal effluent enters R. A.'s ileum.

Simulation of the defect of congenital alkalosis with diarrhea in normal subjects by perfusion of sodium sulfate-sodium phosphate solutions

Sodium bicarbonate absorption. If the sole defect in R. A.'s ileum were the inability to actively absorb chloride, the absorption of sodium bicarbonate from the balanced electrolyte solution by $R$. A. should be simulated by normal subjects perfused with solutions in which chloride is replaced with poorly absorbed anions. In order to assess this possibility, a test solution, similar to the balanced electrolyte solution except for substitution of poorly absorbed sulfate and phosphate for chloride, was perfused in the ileum of 10 normal subjects. Mannitol was added to maintain all test solutions isotonic with plasma. As shown in Table VI, top panel, when this solution was perfused, normal subjects absorbed sodium bicarbonate, acidifying the perfusate. Thus, in the absence of chloride, normal subjects absorb sodium bicarbonate. These results are strikingly similar to the results in $\mathrm{R}$. A. during perfusion of the balanced electrolyte solution (Table II) and indicate that congenital alkalosis with diarrhea can be closely simulated in normal subjects by perfusion of an electrolyte solution in which chloride is replaced by poorly absorbed anions. Absorption of sulfate and phosphate can be quantitated by calculating the anion gap. Thus, sulfate and phosphate absorption together was approximately $0.8 \mathrm{mEq} / \mathrm{hr}$ per $30 \mathrm{~cm}$.

Mechanism of bicarbonate absorption. In order to determine if the mechanism of bicarbonate absorption from the chloride-free solution by normal subjects was hydrogen ion secretion (as in R. A.), lumen $\mathrm{Pco}_{2}$ during bicarbonate absorption was compared with lumen $\mathrm{Pco}_{2}$ when bicarbonate was not being absorbed. This was done by perfusing two chloride-free solutions, one containing bicarbonate, the other containing no bicarbonate. Both solutions contained $14 \mathrm{~mm}$ phosphate (as a nonbicarbonate buffer). Results of these studies in 10 normal subjects are shown in Table VI. As bicarbonate was absorbed from the bicarbonate-containing solution, the $\mathrm{Pco}_{2}$ of ileal perfusate rose to consistently higher levels than during perfusion of the bicarbonatefree solution. Thus, the absorption of bicarbonate by normal subjects was associated with development of a high lumen $\mathrm{P}_{\mathrm{CO}_{2}}$ in the presence of phosphate buffer. This indicates that ileal bicarbonate absorption in the absence of lumen chloride is mediated by hydrogen ion secretion.

$P D$ during bicarbonate absorption. Lumen to skin $P D$ was measured in six normal subjects perfused with these two chloride-free solutions, and the balanced 


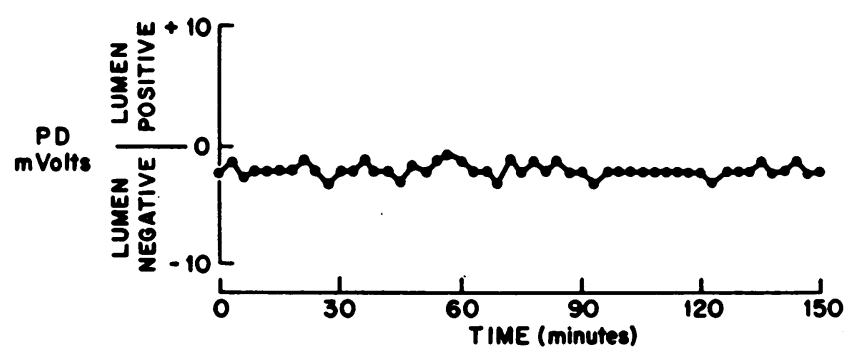

\begin{tabular}{|c|c|c|c|c|c|}
\hline \multirow{3}{*}{$\begin{array}{c}\text { ION } \\
\text { CONCENTRATION } \\
\text { (mEq/liter) }\end{array}$} & 140 & 140 & 140 & 140 & 140 \\
\hline & 0 & 0 & 110 & 0 & 0 \\
\hline & 0 & 30 & 35 & 0 & 30 \\
\hline
\end{tabular}

FIGURE 3 Potential difference (lumen to skin) in a normal subject during perfusion of the two chloride-free solutions (with and without bicarbonate) and a balanced electrolyte solution. Concentration of sodium, chloride and bicarbonate are shown across the bottom. All solutions were isotonic.

electrolyte solution. A representative study is shown in Fig. 3. PD was near zero with all three of these solutions. The five other studies gave similar results. Thus, there is no evidence that the hydrogen ion secretion noted with the chloride-free, bicarbonate-containing solution is down an electrical gradient. The bicarbonate concentration in the studies shown in Table VI fell to an average final concentration of $19 \mathrm{mEq} /$ liter, representing a blood to lumen gradient of 1.3. Such a gradient, achieved passively, would require a lumen to blood PD of at least $8 \mathrm{mv}$, lumen negative.

\section{DISCUSSION}

The defect in congenital alkalosis with diarrhea. These studies demonstrate that R. A.'s ileum lacks the normal ability to absorb chloride actively. However, his ileum is not impermeable to chloride, as clearly shown by the near normal unidirectional chloride fluxes, and by the fact that chloride is readily absorbed or secreted passively in response to electrochemical gradients. The observation that raising lumen bicarbonate concentration increased chloride secretion down a concentration gradient suggests that in R. A., as in normal subjects, at least some passive chloride movement is via a chloride-bicarbonate exchange. The finding of a normal sodium diffusion potential when lumen sodium and chloride concentrations are simultaneously lowered suggests that R. A.'s ileum is able to discriminate between sodium and chloride in a normal manner.

Sodium absorption appears to be intact in R. A. In fact, he absorbed more sodium from the balanced electrolyte solution than did normals. These studies reveal no reason why ileal sodium absorption from the balanced electrolyte solution should be enhanced in R. A. How- ever, because of his diarrhea, he is probably chronically salt depleted, and salt deprivation may indirectly stimulate ileal sodium absorption $(21,22)$.

Potassium appears to be transported passively in R. A., in response to electrochemical gradients. No evidence was found for the presence of an ileal sodium-potassium exchange.

In $\mathrm{R}$. A., sodium absorption was accompanied by bicarbonate absorption, whereas in normal subjects sodium and chloride are absorbed and bicarbonate is secreted. Furthermore, in R. A., but not in normals, lumen bicarbonate is required for sodium absorption to occur. This dependence of sodium absorption on lumen bicarbonate in $\mathrm{R}$. A. indicates that absorption of sodium and bicarbonate are linked. The bicarbonate absorption in R. A. is associated with the development of high lumen $\mathrm{Pco}_{2}$, which suggests that apparent bicarbonate absorption is actually mediated by hydrogen ion secretion rather than transport of the bicarbonate ion itself. Since the hydrogen ion secretion occurred in the absence of a measurable PD across the ileal mucosa, these results, taken together, strongly suggest that $R$. A. absorbs sodium bicarbonate by a sodium-hydrogen exchange.

The results in $\mathrm{R}$. A. can be explained to a remarkable degree by a single derangement in the double exchange model which has been proposed to explain normal ileal electrolyte transport (15). According to this model (Fig. 4, left), the normal ileal anion and cation exchanges operate at approximately the same rate, absorbing sodium and chloride in exchange for secreted hydrogen and bicarbonate. These secreted ions react in the lumen to form water and carbon dioxide. Passive ion movement in response to concentration gradients as well as active ion transport can occur via these exchanges. 

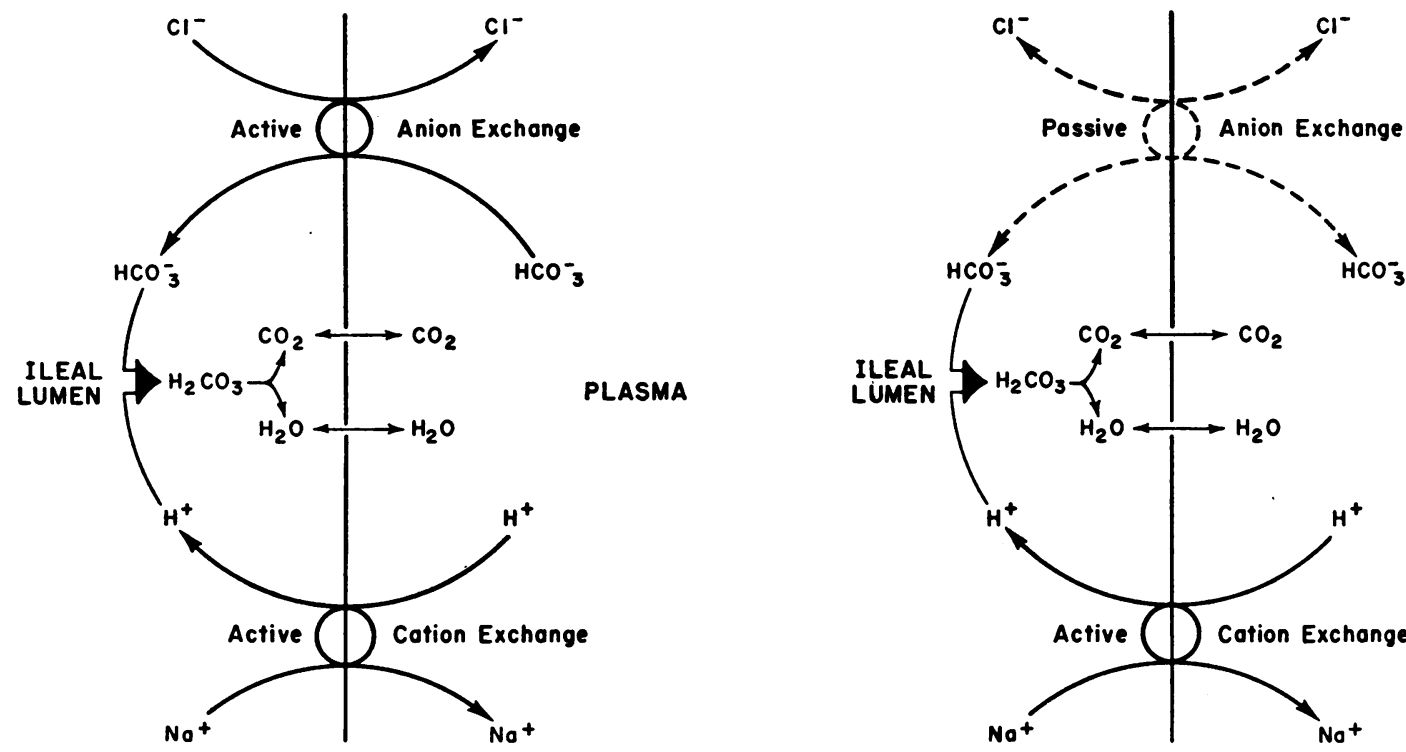

PLASMA

FIGURE 4 A model representing ileal electrolyte transport in normal subjects and in $R$. A. In normal subjects both ion exchanges are active. In the patient with congenital alkalosis with diarrhea the cation exchange is active, but the anion exchange is passive.

The results of the present study suggest, as illustrated on the right side of Fig. 4, that in R. A. the anion exchange is capable of passive but not active transport, while the cation exchange continues to work normally, actively absorbing sodium and secreting hydrogen. Secreted hydrogen reacts with bicarbonate present in the lumen to produce water and carbon dioxide, resulting in apparent sodium bicarbonate absorption.
We propose the following to occur in our patient with congenital alkalosis with diarrhea. Since gastric acid studies and jejunal aspiration revealed normal results, a normal jejunal effluent is assumed to enter the ileum. This effluent would be isotonic to plasma with approximate ion concentrations as follows: sodium concentration $140 \mathrm{mEq} /$ liter, chloride concentration $115 \mathrm{mEq} /$ liter, and bicarbonate concentration $20 \mathrm{mEq} /$ liter. As the fluid en-

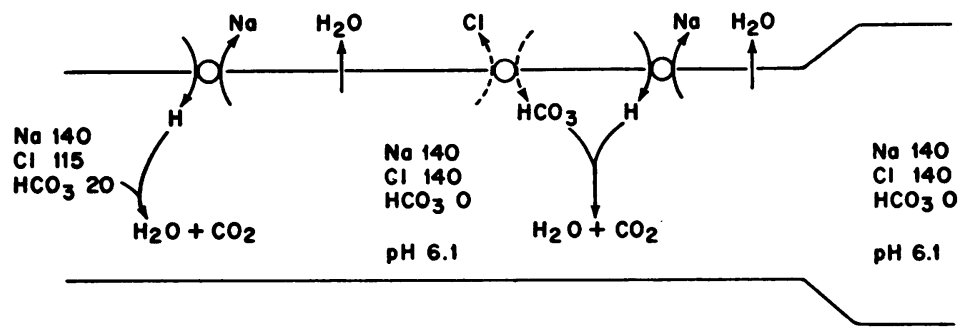

FIGURE 5 Hypothesis for the pathogenesis of congenital alkalosis with diarrhea. Alteration of composition of intestinal contents by ileal electrolyte transport. Composition of jejunal effluent is shown on the left, composition of the ileal effluent on the right. A normal jejunal effluent enters the ileum where the active sodium-hydrogen exchange results in sodium bicarbonate absorption. Sodium absorption stops when lumen bicarbonate is depleted (lumen $\mathrm{pH}$ 6.1), leaving sodium chloride within the ileal lumen. Chloride is then absorbed down its concentration gradient by the passive chloride-bicarbonate exchange. Bicarbonate secreted by this passive exchange allows more sodium absorption and hydrogen secretion to occur. Thus, sodium chloride absorption proceeds, while lumen $\mathrm{pH}$ remains at 6.1 . Ileal effluent thus contains a high chloride concentration and is acidic. 
ters the ileum, as shown in Fig. 5, sodium is actively absorbed in exchange for hydrogen. In contrast to normals, lumen chloride cannot be actively exchanged for bicarbonate. The hydrogen secreted in exchange for sodium reacts with bicarbonate, resulting in a fall in lumen bicarbonate concentration and a fall in $\mathrm{pH}$. When the $\mathrm{pH}$ falls to approximately 6.1 , the sodium-hydrogen exchange stops because of the large adverse hydrogen gradient. However, as sodium bicarbonate and water are absorbed, the lumen chloride concentration rises because of volume contraction. Chloride is then absorbed passively, down its concentration gradient, in exchange for secreted bicarbonate. This secreted bicarbonate raises the luminal $\mathrm{pH}$ slightly and allows more sodium-hydrogen exchange. This process could theoretically continue until virtually all ileal fluid was absorbed, if fluid remained in the ileum indefinitely. However, the rate of fluid absorption would be markedly less than normal for two reasons : first, because the $\mathrm{pH}$ of ileal contents would be 6.1 instead of the normal 7.4-7.5, which would reduce the rate of sodium-hydrogen exchange, and, second, because active chloride absorption is absent. Fluid leaving the ileum would have a chloride concentration approximately equal to the sum of the sodium and potassium concentrations, and would have a $\mathrm{pH}$ of about 6.1. Loss of this fluid as stool would cause a systemic hypochloremic alkalosis.

To what extent the colon is abnormal in this disease is not known; however, the failure of the colon to modify the chloride concentration and $\mathrm{pH}$ of ileal contents suggest that colonic chloride absorption is also defective.

Turnberg recently studied a patient with congenital alkalosis with diarrhea and reported ileal chloride secretion when lumen chloride concentration was $125 \mathrm{mEq}$ / liter. He concluded that his patient's disease was due to the presence of an active chloride-bicarbonate exchange working in the direction of chloride secretion (7). Our patient has been studied on three occasions when lumen chloride concentration was $115-121 \mathrm{mEq} / \mathrm{liter}$. On all three occasions he absorbed (rather than secreted) chloride down an electrochemical gradient. The reason for the discrepancy between Turnberg's and our results is not clear, although we feel confident that our patient does not actively secrete chloride. Further studies will be necessary to determine if Turnberg's and our patient have the same transport defect.

It is of great interest that this ileal disease can be simulated exactly in normal subjects by perfusing a solution in which the poorly absorbable sulfate and phosphate are substituted for chloride. This lends credence to the contention that the ileal defect on congenital alkalosis with diarrhea is entirely explained by the absence of active chloride-bicarbonate exchange.
Relevance to normal physiology. Two models have been proposed to explain normal electrolyte absorption in the ileum. The double exchange model has already been described, and is illustrated in Fig. 4. It is not possible to specify the location of these exchange processes or to equate the exchanges with biochemically characterized membrane electrolyte pumps. The double exchange model describes electrolyte transport between lumen and plasma and components of the model may reside on one or more of the several membranes that separate lumen and plasma. The other model envisions two electrogenic pumps-one for sodium and one for chloride (23). In this second model, both pumps would generate an electrical $\mathrm{PD}$, but if sodium and chloride were absorbed at the same rates, the mucosal negative $\mathrm{PD}$ generated by the sodium pump would be exactly cancelled by the mucosal positive PD generated by the chloride pump.

The study of a patient with a selective defect in active chloride absorption offers a unique opportunity to decide which of these models correctly describes normal ileal electrolyte transport. The observation that bicarbonate absorption in R. A. is associated with a rise in the $\mathrm{PCo}_{2}$ of lumen fluid suggests that bicarbonate removal is due to hydrogen secretion rather than to bicarbonate absorption per se. This would be predicted from the double exchange model. However, apparent bicarbonate absorption due to hydrogen secretion is also compatible with the double electrogenic pump model; i.e., in the absence of active chloride transport, hydrogen secretion could occur in response to a mucosal negative PD generated by the sodium pump.

Thus, the only way to decide which of the two models is correct, from a study of a patient with congenital alkalosis with diarrhea, is to measure ileal PD. The double exchange model would predict a PD near zero, whereas the double electrogenic pump model would predict a mucosal negative $P D$. The minimum values of $P D$ required by the electrogenic pump model to explain the bicarbonate concentration gradient between ileal lumen and plasma in R. A. were calculated to be 21 and $34 \mathrm{mv}$, lumen negative. However, the observed PD values were zero and $3 \mathrm{mv}$, lumen positive. These results strongly support the double exchange rather than the double electrogenic pump model as the explanation for normal electrolyte absorption in the ileum.

Admittedly, this argument rests completely on accurate measurement of mucosal $P D$. However, since we measured ileal PD in R. A. on two separate occasions, and these values agree closely with values calculated from the potassium data, we believe our conclusion is correct. 


\section{ACKNOWLEDGMENTS}

The authors express their appreciation to Dr. Robert S. Gordon for his interest and helpful suggestions and to Raymond Acabbo, Stephen Morawski, Barbara Taylor, Martha Irvin, and Jean Harber for their contribution to these studies and the preparation of the manuscript.

Dr. Bieberdorf was supported by U. S. Public Health Service Training Grant 5 T01 AM 05490 from the National Institutes of Health, and The University of Texas Southwestern Medical School at Dallas General Research Grant 5 S01 RR 0542609.

\section{REFERENCES}

1. Darrow, D. C. 1945. Congenital alkalosis with diarrhea. J. Pediatr. 26: 519.

2. Gamble, S. L., K. R. Fahey, J. Appleton, and E. MacLachlan. 1945. Congenital alkalosis with diarrhea. $J$. Pediatr. 26: 509.

3. Kelsey, W. M. 1954. Congenital alkalosis with diarrhea. Am. J. Dis. Child. 88: 344.

4. Tucker, V. L., D. Wilmore, C. J. Kaiser, and R. M. Lauer. 1964. Chronic diarrhea and alkalosis. Pediatrics. $34: 601$.

5. Owen, G. M. 1964. Metabolic alkalosis with diarrhea and chloride-free urine. J. Pediatr. 65: 849.

6. Evanson, J. M., and S. W. Stanbury. 1965. Congenital chloridorrhea or so-called congenital alkalosis with diarrhea. Gut. 6: 29.

7. Turnberg, L. A. 1971. Abnormalities in intestinal electrolyte transport in congenital chloridorrhoea. Gut. 12 : 544.

8. Fordtran, J. S., F. C. Rector, T. W. Locklear, and M. F. Ewton. 1967. Water and solute movement in the small intestine of patients with sprue. J. Clin. Invest. 46: 287.

9. Schmid, W. C., S. F. Phillips, and W. H. J. Summerskill. 1969. Jejunal secretion of electrolytes and water in nontropical sprue. J. Lab. Clin. Med. 73: 772.

10. Banwell, J. G., N. F. Pierce, R. C. Mitra, K. L. Brigham, G. J. Caranasos, R. I. Keimowitz, D. S. Fedson, J. Thomas, S. L. Gorbach, R. B. Sack, and A. Mondal. 1970. Intestinal fluid and electrolyte transport in human cholera. J. Clin. Invest. 49: 183.
11. Banwell, J. G., S. L. Gorbach, N. F. Pierce, R. Mitra, and A. Mondal. 1971. Acute undifferentiated human diarrhea in the tropics. II. Alterations in intestinal fluid and electrolyte movements. J. Clin. Invest. 50: 890.

12. Fordtran, J. S., F. C. Rector, and N. W. Carter. 1968. The mechanisms of sodium absorption in the human small intestine. J. Clin. Invest. 47: 884.

13. Hyden, S. 1965. A turbidometric method for the determination of higher polyethylene glycols in biologic materials. Ann. Roy. Agr. Coll. Swed. 22: 139.

14. Berger, E. Y., and J. M. Steele. 1958. The calculation of transfer rates in two compartment systems not in dynamic equilibrium. J. Gen. Physiol. 41: 1135.

15. Turnberg, L. A., F. A. Bieberdorf, S. G. Morawski, and J. S. Fordtran. 1970. Interrelationships of chloride, bicarbonate, sodium, and hydrogen transport in the human ileum. J. Clin. Invest. 49: 557.

16. Fordtran, J. S., and T. W. Locklear. 1966. Ionic constituents and osmolality of gastric and small-intestinal fluids after eating. Am. J. Dig. Dis. 11: 503.

17. Moore, E. W., and R. W. Scarlata. 1965. The determination of gastric acidity by the glass electrode. Gastroenterology. 49 : 178.

18. Turnberg, L. A., J. S. Fordtran, N. W. Carter, and F. C. Rector, Jr. 1970. Mechanism of bicarbonate absorption and its relationship to sodium transport in the human jejunum. J. Clin. Invest. 49: 548.

19. Fordtran, J. S., and F. J. Ingelfinger. 1968. Absorption of water, electrolyte, and sugars from the human gut. Handb. Physiol. 3 (Sect. 6) : 1457.

20. Phillips, S. F., and W. H. J. Summerskill. 1967. Water and electrolyte transport during maintenance of isotonicity in human jejunum and ileum. J. Lab. Clin. Med. 70: 686.

21. Gallagher, N. D., D. D. Harrison, and A. P. Skyring. 1962. Fluid and electrolyte disturbances in patients with long-established ileostomies. Gut. 3: 219.

22. Clarke, A. M., G. L. Hill, and W. A. A. G. Macbeth. 1967. Intestinal adaptation to salt depletion in tient with an ileostomy. Gastroenterology. 53: 444.

23. Schultz, S. G., and P. F. Curran. 1968. Intestinal absorption of sodium chloride and water. Handb. Physiol. 3 (Sect. 6) : 1245 . 